\title{
Hepatitis C (HCV) and human immunodeficiency virus (HIV) infections promote liver fibrosis development by potentiation of liver cell death
}

\section{Editorial}

HIV and HCV is an often combination, with 7 million people being co-infected worldwide. This co-infection accelerates liver fibrosis even when HIV-replication is controlled by anti-retroviral therapy (ART). ${ }^{1}$ The alarming factor for co-infection is a high incidence of decompensated liver cirrhosis and $\mathrm{HCC}$, which exceeds the one in mono-infections. ${ }^{2}$ In the liver, only hepatocytes are productively infected with $\mathrm{HCV}$, while the productive infection of other cell types is questionable. HCV induces oxidative stress and apoptosis in hepatocytes. ${ }^{3}$ In contrast to $\mathrm{HCV}$, the level of HIV infection in hepatocytes is low or this infection is even latent. ${ }^{4,5}$ While immune cells expressing CD4 receptor are HIV-permissive, liver transaminases are frequently elevated in the sera of HIV-infected patients even in the absence of accompanying viral hepatitis, ${ }^{6}$ and there is an association between HIV RNA content in the cells and liver fibrosis. ${ }^{5}$ Hepatocytes are mildly damaged by HIV-1, but the exposure of HCV-pre-sensitized hepatocytes to HIV leads to increased hepatocyte damage. ${ }^{7,8}$

\section{The liver and activated immune cells}

Due to its central anatomical position, the liver plays a significant role in the maintenance of immune responses to HIV, since it is largely responsible for the clearance of virus from the bloodstream and is supplemented by activated immune cells originated from the gut. ${ }^{9}$ The liver is considered as a graveyard of activated immune cells that are attracted to dying (apoptotic) hepatocytes and to chemoattractants released by non-parenchymal cells (NPC). ${ }^{10,11}$ In the liver, there is accumulation of HIV-activated immune cells, and these cells undergo apoptosis. ${ }^{12}$ In addition to apoptotic hepatocytes, immune cells themselves become a significant source of apoptotic bodies in this organ.

\section{Liver fibrosis}

Accompanies intensive hepatocyte death and is characterized by enhanced synthesis and secretion of extracellular matrix (ECM) proteins and its reduced degradation. The main source of ECM during fibrogenesis are hepatic stellate cells (HSC). Fibrosis occurs when ECM proteins accumulate in excessive amounts leading to scarring that increases tissue stiffness. ${ }^{13}$ To reverse fibrosis, degrading ECM matrix metalloproteinases (MMPs) must overcome the effects of tissue inhibitors of MMPs (TIMPs). ${ }^{14}$ When apoptosis is massive, apoptotic bodies are captured by liver NPC, Mph and HSC, thereby inducing inflammation and fibrosis. ${ }^{15-17}$ After massive hepatocyte death, the HSCs are activated into proliferative, fibrogenic and contractile myofibroblasts expressing prostaglandin D receptor that actively produce ECM components, such as type I collagen. Numerous cytokines (like TGF $\beta$ ) activate HSC for pro-inflammatory response. HIV-1 was reported to infect HSCs in a CD4/chemokine receptor independent manner, resulting in increased expression of collagen-1 and the pro-inflammatory monocyte chemoattractant protein 1 (MCP1). ${ }^{18}$ Inflammasome (IFS) plays a role in pro-inflammatory activation
Volume 9 Issue 2 - 2018

\author{
Natalia Osna, Larisa Poluektova \\ Research Service, Veterans Affairs Nebraska-Western lowa \\ Health Care System, 4101 Woolworth Ave, Omaha, NE 68I05, \\ USA; University of Nebraska Medical Center, Omaha, NE 68105, \\ USA.
}

Correspondence: Natalia Osna, MD, Ph.D,VA Medical Center, RI5I, 4 I 0 I Woolworth Ave, Omaha, NE 68I05, US. Phone I-402-995-3735, Fax I-402-346-8800, Email nosna@unmc.edu

Received: March 19,2017 | Published: April 10, 2018

of HSC. ${ }^{19}$ Also, increased density of matrix during liver fibrosis leads to increasing liver stiffness, which is now believed to correlate and contribute to the progression of liver fibrosis.

\section{HIV potentiates fibrosis progression un HCV-infected livers}

Recently, we have shown that co-infection of hepatocytes with $\mathrm{HIV}$ and HCV induces prominent apoptosis in these cells, and apoptotic bodies engulfed by HSC promote the production of ECM. Interestingly, apoptotic bodies generated from hepatocytes serve as more efficient pro-fibrotic triggers than apoptotic immune cells, which induce pro-inflammatory effects. These effects are HIV-and $\mathrm{HCV}$-specific since the magnitude of pro-fibrotic response is lower when apoptotic bodies were made from HIV-and HCV-negative hepatocytes. To ensure long-term persistence and efficient infection of hepatocytes in cells culture, we have used Huh7.5 cells transfected with CYP2E1 (named RLW cells) and plated on synthetic 2D gels, which makes cultured cells hepatocyte-like. ${ }^{20,21}$ The obtained data allowed hypothesizing that HIV infection of hepatocytes followed by apoptotic cell death plays a substantial role in the progression of HCV-triggered liver injury. This "second hit" system based on interaction between double-infected apoptotic liver parenchymal and non-parenchymal cells is crucial for further fibrosis development.

\section{Taken together}

Co-infection of hepatocytes with HIV and HCV induces apoptotic cell death; Internalization of these apoptotic bodies by hepatic stellate cells promotes liver fibrosis development.

\section{Acknowledgements}

None.

\section{Conflict of interest}

The author declares no conflict of interest. 


\section{References}

1. Hernandez MD, Sherman KE. HIV/hepatitis C coinfection natural history and disease progression. Curr Opin HIV AIDS. 2011;6(6):478-482.

2. Brau N, Fox RK, Xiao P. et al. Presentation and outcome of hepatocellular carcinoma in HIV-infected patients: a US-Canadian multicenter study. $J$ Hepatol. 2007;47(4):527-537.

3. Mastroianni CM, Lichtner M, Mascia C, et al. Molecular mechanisms of liver fibrosis in HIV/HCV coinfection. Int J Mol Sci. 2014;15(6):91849208 .

4. Cao YZ, Friedman-Kien AE, Huang YX, et al. CD4-independent, productive human immunodeficiency virus type 1 infection of hepatoma cell lines in vitro. J Virol. 1990;64(6):2553-2559.

5. Kong L, Walter Cardona Maya, Maria E Moreno-Fernandez, et al. Lowlevel HIV infection of hepatocytes. Virol J. 2012;9:157.

6. Mata-Marin JA, Gaytán-Martínez J, Grados-Chavarría BH, et al. Correlation between HIV viral load and aminotransferases as liver damage markers in HIV infected naive patients: a concordance cross-sectiona study. Virol J. 2009;6:181.

7. Bruno R, Sacchi P, Puoti M, et al. Pathogenesis of liver damage in HCVHIV patients. AIDS Rev. 2008;10(1):15-24.

8. Hu S, Marwan Ghabril, Tohti Amet, et al. HIV-1 coinfection profoundly alters intrahepatic chemokine but not inflammatory cytokine profiles in HCV-infected subjects. PLoS One. 2014;9(2):e86964.

9. Evans TI, Li H, Schafer JL, et al. SIV-induced Translocation of Bacterial Products in the Liver Mobilizes Myeloid Dendritic and Natural Killer Cells Associated With Liver Damage. J Infect Dis. 2016;213(3):361-369.

10. Huang L, Soldevila G, Leeker M, et al. The liver eliminates T cells undergoing antigen-triggered apoptosis in vivo. Immunity. 1994;1(9):741749.

11. Sopper S, Nierwetberg D, Halbach A, et al. Impact of simian immunodeficiency virus (SIV) infection on lymphocyte numbers and T-cell turnover in different organs of rhesus monkeys. Blood. 2003;101(4):12131219.
12. Ahsan MH, Amy F Gill, Andrew A, et al. Acute and chronic T cell dynamics in the livers of simian immunodeficiency virus-infected macaques. $J$ Virol. 2012;86(9):5244-5252.

13. Cordero-Espinoza L. Huch M. The balancing act of the liver: tissue regeneration versus fibrosis. J Clin Invest. 2018;128(1):85-96.

14. Iimuro Y, Nishio T, Morimoto T, et al. Delivery of matrix metalloproteinase-1 attenuates established liver fibrosis in the rat. Gastroenterology. $2003 ; 124(2): 445-458$

15. Dalton SR, Wiegert RL, Baldwin CR, et al. Impaired receptor-mediated endocytosis by the asialoglycoprotein receptor in ethanol-fed mice: implications for studying the role of this receptor in alcoholic apoptosis. Biochem Pharmacol. 2003;65(4):535-543.

16. Mehal W, Imaeda A. Cell death and fibrogenesis. Semin Liver Dis. 2010;30(3):226-231.

17. Patel P, Khan N, Rani M, et al. The expression of HIV-1 Vpu in monocytes causes increased secretion of TGF-beta that activates profibrogenic genes in hepatic stellate cells. PLoS One. 2014;9(2):e88934.

18. Tuyama AC, Hong F, Saiman Y, et al. Human immunodeficiency virus (HIV)-1 infects human hepatic stellate cells and promotes collagen I and monocyte chemoattractant protein-1 expression: implications for the pathogenesis of HIV/hepatitis C virus-induced liver fibrosis. Hepatology. 2010;52(2):612-622.

19. Watanabe A, Sohail MA, Gomes DA, et al. Inflammasome-mediated regulation of hepatic stellate cells. Am J Physiol Gastrointest Liver Physiol. 2009;296(6):G1248-1257.

20. Kidambi S, Chan C, Lee I. Selective depositions on polyelectrolyte multilayers: self-assembled monolayers of m-dPEG acid as molecular template. J Am Chem Soc. 2004;126(14):4697-4703.

21. Kidambi S, Yarmush RS, Novik E, et al. Oxygen-mediated enhancement of primary hepatocyte metabolism, functional polarization, gene expression, and drug clearance. Proc Natl Acad Sci USA. 2009;106(37):15714-15719. 